\title{
Consumers' Travel Behavior to Shopping Centers
}

\author{
Yumeng Liu* \\ Institute of Human Geography of Tourusm, Xi'an International Studies University, China \\ *Corresponding author: Yumeng Liu, 107242019200228@stu.xisu.edu.cn
}

\begin{abstract}
Based on the questionnaire data, this study analyzes the characteristics of Wuhu citizens' travel behavior in shopping centers. The following conclusions are drawn: (1) the frequency of trips to shopping centers has a great correlation with consumers' economic level and social status; (2) the time spent to purchase goods is positively correlated with the level of goods; (3) multipurpose shopping becomes the mainstream; (4) traffic becomes the primary factor for consumers to consider; (5) the availability of supermarkets and cinemas at shopping centers affect consumers' choice of shopping centers.
\end{abstract}

Keywords: Shopping center; Travel behavior; Consumers

Publication date: October 2021; Online publication: October 29, 2021

\section{Research background}

Early research on shopping behavior originated from the research on urban commercial space, focusing on the dynamic balance relationship between supply and demand. Reilly used the law of retail gravity to define the scope of business circle and put forward the concept of rational economy as well as space invariant, assuming that consumer behavior is rational and has invariance in space ${ }^{[1]}$. Thereafter, the central place theory proposed by Kristol introduced the hypothesis of neoclassical economics, where both producers and consumers are considered as "reasonable people" in economic behavior, in which they would consciously choose the nearest central place to purchase goods or obtain services. This has a profound influence on the later research on shopping behavior ${ }^{[2]}$. It can be seen that earlier studies focused on the supply level but did not assume "behavior" as their research subject.

With the development of behavioral geography, the assumption of "economic man" in the central geography theory began to loosen, and consumers began to be included in the research system as direct research subjects ${ }^{[3]}$. Huff proposed a probability model based on the modification of Riley's gravity model, which focuses on consumers rather than retailers, thus encouraging consumer behavior research. Rushton introduced the explicit spatial preference, which suggests that place preference has a greater impact on consumers compared to objective location ${ }^{[4]}$. In addition, many scholars began to study and predict consumers' choice of shopping centers from the perspective of shopping behavior and proved that different consumers would choose different shopping centers. At this point, the theoretical system of shopping behavior has been formed, and the mainstream of research has shifted from commercial space to shopping behavior ${ }^{[5]}$.

\section{Data and methods}

\subsection{Overview of the location}

Located in the southeast of Anhui Province, Wuhu is a port city along the Yangtze River. In recent years, a number of large shopping centers have settled here with an increasing number of residents which prefer large shopping centers for shopping, leisure, entertainment, and other activities. 


\subsection{Data source}

In consideration of the definition of "large shopping center" by China's Ministry of Commerce and the actual situation of Wuhu, this study defines "shopping center" as a commercial complex with a floor area of more than 80,000 square meters and a variety of retail stores and service facilities in one building or one area to provide comprehensive services to consumers. This kind of commercial assembly usually has dozens or even hundreds of service facilities, including large supermarkets, specialized stores, exclusive stores, restaurants, grocery stores, entertainment facilities, fitness facilities, leisure facilities, etc., with parking lots of a certain scale ${ }^{[6]}$.

A survey was conducted at all shopping centers and large shopping centers in Wuhu (till 2018). In July 2018, a sampling questionnaire survey on the travel behavior of Wuhu residents in large shopping centers was carried out, with a total of 944 valid questionnaires.

\subsection{Demographic information}

The demographics of the respondents are shown in Table 1. The survey included the monthly travel of the residents in Wuhu to large shopping centers, the number of shopping centers, the duration of the average consumption in those shopping centers, shopping destination choice, frequency, etc.

Table 1. Demographic information of the respondents

\begin{tabular}{cccc}
\hline Demographic information & Category & Number of samples & Percentage (\%) \\
\hline Gender & Male & 358 & 38 \\
& Female & 586 & 62 \\
\hline Occupation & Civil servants & 17 & 1.8 \\
& Students & 271 & 28.7 \\
& Private owners & 102 & 10.8 \\
& Cultural, educational, & 120 & 12.7 \\
& and scientific research personnel & & \\
& Ordinary workers & 52 & 5.5 \\
& Retired & 19 & 2 \\
& Others & 75 & 7.9 \\
\hline Age & Below 18 & 116 & 12.3 \\
& 18 to 25 years old & 415 & 44 \\
& 26 to 35 years old & 264 & 28 \\
& 36 to 45 years old & 95 & 10 \\
& 46 to 55 years old & 36 & 3.8 \\
& 56 years of age or older & 18 & 1.9 \\
\hline Less than 1,000 & 315 & 33.4 \\
& $1000-3000$ & 250 & 26.5 \\
Average monthly income & $3000-5000$ & 252 & 26.7 \\
& $5000-7000$ & 80 & 8.5 \\
& More than 7000 & 47 & 4.9 \\
\hline
\end{tabular}




\section{Analysis of location selection characteristics}

\subsection{Characteristics of consumption facilities selection in large shopping centers}

In the survey of consumers' choice of consumption facilities in shopping centers, $31 \%$ of consumers chose supermarkets and 32\% chose cinemas. In regard to the supporting facilities that should be provided in shopping centers, $25 \%$ of consumers chose catering facilities, $23 \%$ chose bus terminals, and $19 \%$ chose entertainment facilities and parking.

\subsection{Characteristics of large shopping center selection}

In the survey of the most frequently visited shopping centers by consumers, Wanda Plaza and Suning Plaza accounted for $23.41 \%$, respectively, while Intime, Huayi, Xinbai, and Huaqiang accounted for $16.31 \%$, $7.62 \%, 6.14 \%$, and 5.93\%, respectively. On the other hand, Bozhuang Times Square, Kaide Square, and Liansheng International are relatively single while lacking leisure and entertainment shops as well as restaurants. The new 100 Building and Golden Eagle International belong to the old-school department store, in which they have modest themes. Wanda Plaza, Yintai City, Suning Square, Huaqiang Square, and Huayi International have underground parking lots. There are more than 5 bus stops and 8 bus routes within a 400-meter range around the shopping center.

\subsection{Analysis of the factors affecting the choice of shopping centers}

Table 2. Selection factor evaluation of large shopping centers

\begin{tabular}{|c|c|c|c|c|}
\hline Selection factor & Sample mean & Mean & Standard & Overall evaluation \\
\hline Closer distance & 944 & 4.11 & 1.08 & Important \\
\hline Convenient transportation & 944 & 4.35 & 0.85 & Very important \\
\hline Performance of goods & 944 & 4.02 & 0.99 & Important \\
\hline Variety of goods & 944 & 4.26 & 0.86 & Very important \\
\hline Good quality & 944 & 4.21 & 0.88 & Very important \\
\hline Offer a certain brand & 944 & 4.02 & 0.99 & Generally important \\
\hline Good service quality & 944 & 4.25 & 0.90 & Very important \\
\hline Good parking facilities & 944 & 3.75 & 1.15 & Generally Important \\
\hline Supporting facilities & 944 & 4.15 & 0.94 & Important \\
\hline Closing time & 944 & 3.76 & 1.09 & Generally important \\
\hline Good environment & 944 & 3.99 & 0.94 & Generally important \\
\hline High-profile & 944 & 4.01 & 1.01 & Important \\
\hline High credibility & 944 & 4.19 & 0.92 & Important \\
\hline Accustomed to the & 944 & 4.23 & 0.97 & Very important \\
\hline
\end{tabular}

The Likert scale analysis is shown in Table 2. This shows that with the gradual improvement of Wuhu's transportation network, distance is no longer the main factor for consumers in choosing shopping centers. Instead, it is whether the traffic around the shopping centers is developed, whether there are sufficient bus stations, and whether the road system is well-developed. Based on the analysis of the standard deviation of importance, only four selection factors have standard deviation above 1, which indicates that there are great differences in consumers' choice due to those four factors. According to the occupation and the age of the consumers who filled in the questionnaire, it can be appreciated that people without cars, such as students and retired people, do not mind whether there are parking facilities or not, whereas most young employees 
who have private-owned cars pay more attention to this factor. In addition, young people pay more attention to the popularity and closing time of shopping malls, while middle-aged and elderly people have different views in regard to these factors ${ }^{[7]}$.

\section{Temporal and spatial characteristics of consumers' travel to large shopping centers}

\subsection{Characteristics of stay time in shopping centers}

Consumers who shop for basic necessities usually spend 30 to 60 minutes as food, vegetables, and daily necessities are of a relatively low commodity. The stay time for consumers to purchase clothing or accessories is usually 60 to 120 minutes, and there are a few consumers who would stay for more than 120 minutes, mainly because clothing products are high-grade goods and are closely related to consumers' social class, economic income status, and occupation ${ }^{[8]}$. The stay time for consumers to purchase household appliances is 120 to 180 minutes. Household appliances are also high-grade goods in durable consumer goods, so consumers would usually spend a longer time shopping. In regard to those products, consumers tend to choose shopping centers with high performance, good reputation, and excellent after-sales service.

\subsection{Characteristics of time utilization during shopping}

On the whole, travel activities on rest days are generally higher than those on working days because consumers are restricted by fixed working hours or studying hours ${ }^{[9]}$. From the content of activities, the shopping time of consumers on weekdays and rest days has a great difference. On weekdays, there are more consumers in the afternoon, after work, and they would usually purchase low commodity goods. On the other hand, during rest days, consumers tend to make trips to shopping centers at 9:30 and 11:30 in the morning as well as 5:30 in the evening. This is because during their off days, they have plenty of time for shopping; thus, consumers would choose to purchase high-grade goods, such as clothing, household appliances, etc. on rest days. In addition, consumers also tend to engage in leisure and entertainment activities during their off days, after a busy week of studying or working. It can be appreciated that during off days, the multipurpose shopping behavior among consumers is more obvious.

This research found that consumers mostly shop while taking time for leisure and entertainment. Most of them assume catering, daily necessities, clothing, and entertainment as the main purpose to make trips to shopping centers. The proportion of multipurpose shopping has increased significantly.

\subsection{Characteristics of consumers' travel mode and travel distance to large shopping centers}

From Figure 1 and Figure 2, most consumers consider traffic as the main factor. Therefore, the traffic condition, provision of bus stops, and development of road system around shopping centers are the main factors influencing consumers' travel to shopping centers ${ }^{[10]}$. It has been found that large shopping centers have higher travel efficiency, and consumers are still willing to pay more for transportation even though the distance is greater. Walking is one of the main ways for consumers to travel to shopping centers, which reflects that Wuhu's commercial service network facilities are relatively ideal, thus bringing convenience to its residents. 


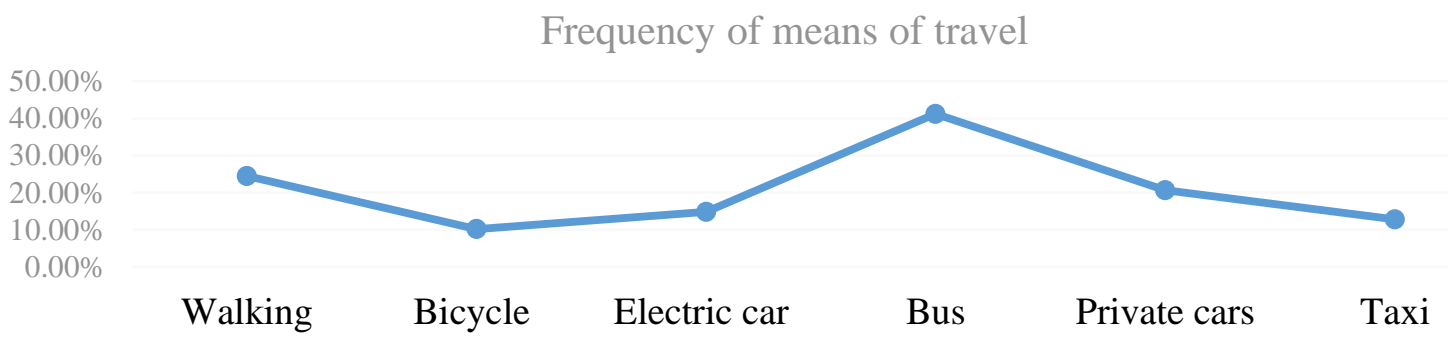

Figure 1. Frequency of means of travel

\section{Frequency of travel distance}

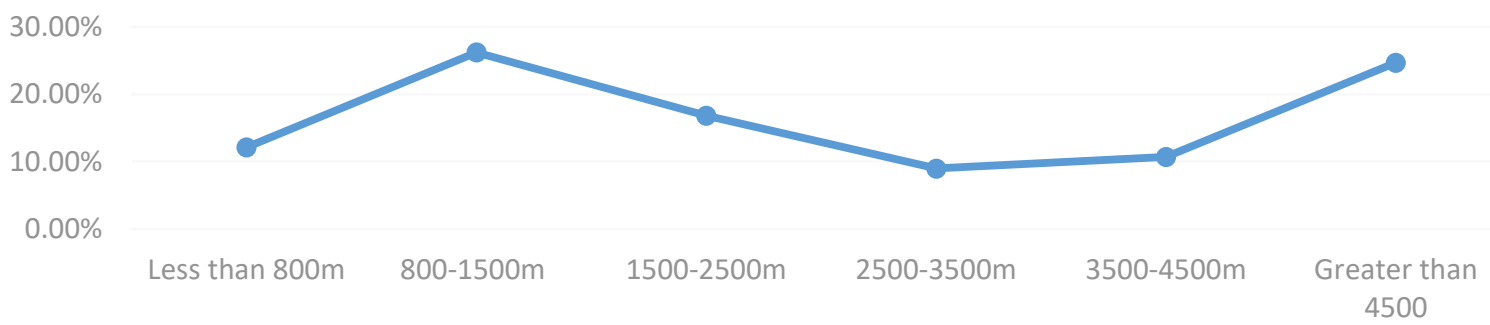

Figure 2. Frequency of travel distance

\section{Discussion and conclusion}

Firstly, the frequency of trips to shopping centers has a significant correlation with consumers' economic level and social status. The time spent by consumers to purchase goods of different grades varies with a positive correlation between them; the higher the grade of goods, the more time it takes to purchase these goods. Clothing products are high-grade goods and are closely related to consumers' social class, economic income status, and occupation, so consumers would usually spend more time purchasing these products. Consumers who engage in other leisure activities also spend more time in shopping centers.

Second, travel activities on rest days are generally higher than those on weekdays. Third, the proportion of multipurpose shopping has increased significantly, showing that consumer behavior has changed, from purchasing daily necessities and clothing in the past to now, purchasing supplies, dining, and seeking entertainment leisure as the auxiliary pattern of shopping. In addition, the level of secondary consumption is mainly concentrated between 200 yuan and 400 yuan.

Fourth, traffic has become the most important factor for consideration among consumers. Most consumers would use the bus as their main mode of travelling.

Fifth, the availability of supermarkets or cinemas in shopping centers greatly affects consumers' choice of shopping centers. The variety of business forms also affects their choices. Shopping centers with diversified business forms can attract consumers from all distances for leisure and shopping activities.

\section{Disclosure statement}

The author declares that there is no conflict of interest.

\section{References}

[1] Huff DL, 1963, A Probabilistic Analysis of Shopping Center Trading Area. J Land Economics, 39(1): 
$81-90$.

[2] Rushton G, 1969, Analysis of Spatial Behavior by Revealed Space Preference. J Annals of the Association of American Geographers, 59(2): 391-400.

[3] Golledge GR, Rushton G, Clark WAV, 1966, Some Spatial Characteristics of Iowa's Farm Population and Their Implications for the Grouping of Central Place Functions. J Economic Geography, 42(3): 261-272.

[4] Wang D, 2001, Analysis of Consumer Travel Characteristics and Commercial Spatial Structure in Shanghai. J City Planning Review, (10): 6-14.

[5] Chai YW, Shen J, Weng GL, et al., 2008, Temporal and Spatial Characteristics of Shopping Behavior and Its Influencing Factors in Shanghai. J Economic Geography, 28(2): 112-117.

[6] Chai Y, Weng G, Gong H, 2004, The Temporal and Spatial Characteristics of Residents' Shopping and Consumption Behavior in Shenzhen. J Human Geography, 19(6): 79-84.

[7] Wu Z, Chai Y, Zhang Z, 2000, Study on the Characteristics of Tianjin Citizens' Shopping Behavior. Geographical Science, 20(6): 534-539.

[8] Wang D, Zhang M, Cai J, et al., 2009, Spatial Characteristics of Consumer Behavior in Beijing Wangfujing Street. Human Geography, 24(3): 27-31.

[9] Chai Y, Li C, 2005, Spatial Characteristics of Daily Shopping Behavior of the Elderly in Chinese Cities: A Case Study of Beijing, Shenzhen and Shanghai. J Acta Geographica Sinica, 60(3): 398-406.

[10] Ma J, Chai Y, 2011, A Comparison of Spatial Decision Factors and Differences between Residents Shopping on Rest Days and Working Days. Scientia Geographica Sinica, 31(1): 29-35. 